\title{
THE STRATEGY OF PKP S.A. AS AN INSTRUMENT OF POLISH RAILWAY TRANSPORT DEVELOPMENT
}

\begin{abstract}
The author of the article discusses the principles of the Strategy of PKP S.A. for the years 2016-2020 and the main areas of business activity of PKP S.A. and the PKP Group which derive the Strategy, for example, property management, innovation, cargo logistics and implementing objectives of the national transport policy. The author indicates the necessity to rationalize the PKP Group management through creating a structure that would operate as a holding company. The article concludes that implementation of the Strategy will ensure proper preparation of the Polish railway transport for the upcoming challenges. Macroeconomic trends clearly indicate the necessity to develop multimodality of passenger and freight transport, and the PKP Group takes them into account. The article pays particular attention to the concept of the Physical Internet in railway transport logistics by presenting the key objectives and benefits of the idea of the Physical Internet in railway transport based on the author's own research and on analysis of the available external research sources ${ }^{1}$.
\end{abstract}

Keywords: Physical Internet, multimodal transport, modular containers, railways, freight, Poland, strategy, sustainable transport

JEL: F23, L92, O52, O53, R11, R12, R41, R42

\section{Introduction}

The Strategy of PKP S.A. ${ }^{2}$ for the years 2016-2020 (with a perspective up to 2023) determines the directions of development for PKP S.A. as well as companies

1 The article uses elements of the presentation at INNOTRANS Fair 2018 (Antonowicz, 2018).

2 PKP S.A. is the company's proper name and it will be used in this article in the full form, note that S.A. in Polish stands for a joint-stock company. 
in the PKP Group. The strategy has been based on the knowledge and experience from the preceding years. It also takes into consideration the regulatory environment and the dynamically changing market environment. The tasks presented in the Strategy derive from the analysis conducted previously and address the actual and future potential inefficiencies within the business areas of PKP S.A. as well as in the entire PKP Group. The performance of tasks within the specified timeframe assumed in the Strategy is aimed at improving and developing the Polish railway infrastructure. This will allow improving the competitiveness of this transport sector and therefore meeting the expectations of benefits to the society and the economy. The Strategy contemplates specific activities and tools to ensure long-term development of the company's economic activities as well as to support the continuous growth in general. Logistics, as part of the Strategy, is understood as a tool to restore the proper position of railways within the flow of domestic and international cargo streams.

This article presents the principles of the Strategy of PKP S.A. and the main areas of business activity of PKP S.A. and the PKP Group which derive from it. Particular attention is paid to the challenges related to increasing the efficiency of logistics processes in freight transport and the idea of the Physical Internet serving this purpose. The article defines the concept of the Physical Internet in cargo logistics and the potential benefits of its implementation in the PKP Group based on the author's own research and other available sources.

\section{Starting point for the Strategy of PKP S.A.}

Experiences of the past 15 years identify the aspirations and challenges for the activity of PKP S.A. and companies in the PKP Group. Today's shape of the PKP Group is mainly determined by changes which were implemented through the Act on commercialization and restructuring of "Polskie Koleje Państwowe" [Polish National Railways] state-owned company of 2000. The PKP Group management system is disintegrated and does not support the coordination of operations of each economic entity. Although the operation of those companies is based on the commercial law and in accordance with formal requirements, it does not ensure reaching the social and economic objectives of Polish railways, which could be met only by a providing proper level of integrity between the companies of the PKP Group.

PKP S.A. is one of the largest property owners in Poland. The Company's assets constitute both facilities related to transport and passenger service functions (railway stations) as well as commercial properties. In order to obtain a long-running benefit, a strategic objective for PKP S.A. is management of items of property having both transport and logistics potential while cooperating with various external partners.

A necessary direction of the PKP Group's activities is also further improvement of the quality of freight and passenger services. A significant development opportunity for railway transport is transport multimodality, meaning a combination of more than just one transport sector for the transport of freight and passengers. A key component of multimodality and the sine qua non condition for its success are nodal infrastructure facilities which could ensure freight and passenger transfer 
between different transport modes. Those facilities are most importantly logistic centres and handling terminals, including freight transport as well as railway stations acting as multimodal transfer hubs for passengers.

The continuously changing trends within mobility create new challenges for railway stations. An increase in the demand for alternative methods of travelling can be observed. Passengers willingly use new services such as car sharing, car rental and city bike systems. All those phenomena inspire constant improvement of the quality of service at railway stations and cause improved integration of stations with the surroundings. Railway stations should encourage the use of the public transport while providing the necessary comfort and enabling an effective transfer between different modes of transport.

\section{Basic areas of the Strategy of PKP S.A.}

The structure of the Strategy of PKP S.A. covers domains, strategic objectives and tasks. The methodological assumptions of the Strategy implementation are based on the Balanced Scorecard (BSC) concept, in accordance with which appropriate indicators have been assigned to strategic objectives and tasks. The Mission of the PKP Group and PKP S.A. described by the Strategy is "creation and development of national railways understood as a basic component of the national logistics system and moreover as a part of the European railways system that ensures the highest possible quality of passenger and cargo transport and logistics services achieved while respecting the rules of sustainable growth and the economic operating efficiency under the open market economy" (The Strategy of PKP S.A., 2018).

The strategy indicates the following areas of business activities of the PKP Group and PKP S.A.:

1. The area of economic and administrative tasks that results from the continuation of the former obligations of PKP as a state-owned company. The area includes the supervisory activities of PKP S.A. over the entire PKP Group, aimed at meeting the business objectives thereof. The strategy of PKP S.A. defines the key business objectives of subsidiaries which will be subject to assessment by the corporate authorities of the PKP Group.

2. The business area related to PKP S.A. asset management. This area indicates objectives and tasks related to improving rationality in the field of management of the property owned by PKP S.A. The objectives are a long-term asset management strategy and maximization of profits from business operations through active development of the portfolio of asset management forms with the use of both the Company's own and external capital.

3. The area of creating innovative transport and logistics products available on national and foreign markets, using the economic potential of companies, both belonging to and outside of the PKP Group. Creating new areas of business operations within the PKP Group will provide additional benefits that will ensure long-term financing for the Polish railway infrastructure development. The PKP Group is interested in implementing sharing economy and innovative 
services based on this idea (e.g., car-sharing, bike-sharing, co-working) as it is a significant trend in the segment of passenger services. A valid objective is also ensuring a service standard compliant with the demands of railway station users, including the operation of customer service points "InfoDworzec", standardization of crisis response procedures, provision of aid for persons with reduced mobility and further adjustment of railway stations to their needs. The IDS concept developed by PKP S.A. - the acronym IDS (Innowacyjny Dworzec Systemowy) is translated as an "innovative modular railway station" - takes into account issues of safety, ergonomics, user convenience, digitization as well as energy saving technologies at railway stations, which lower the operational costs of those facilities.

4. The area of creating business activity within cargo logistics. In order to create conditions for such activity, it is recommended to establish an entity that would act as a logistics integrator connecting the logistics system participants, i.e. clients, various transport sector carriers and handling infrastructure owners, which would make it possible to shape a new, non-standard offer of comprehensive door-to-door logistics services provided under the PKP brand. The integrator would make it possible to shape a new, non-standard transport and logistics services supply chain offer. Its objective would be to act as a logistics platform operating based on "stock exchange" rules where every party interested in moving goods or materials would have the opportunity of choosing the preferred method of transport and handling (supply chain configuration).

5. The area of implementing the objectives of the national transport policy within the railway transport, including multimodal transport. A perfect example of implementing the objectives of this area is the PKP Group's project "Wspólny

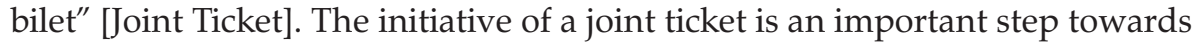
ensuring a friendly railway transport offer. In light of the implementation of the national transport policy a priority task for PKP S.A. is improving the technical and functional condition of railway stations. The operation of railway stations is not only a business matter for the railways, but also a matter of accomplishing a public mission. As a part of the adopted comprehensive investment programme (PID - Program Inwestycji Dworcowych [Railway Station Investment Programme]) the company will reconstruct or build approximately 200 facilities until the end of the current European Union financing perspective. Those investments will mostly be financed by European funds with the usage of government and company own funds and one of its main goals is to adapt the new and existing infrastructure to the needs of persons with reduced mobility and reducing inconveniences related to transport, meaning that it should minimize the time and effort of passengers associated with the journey. The answer is to build transport and transfer centres (multimodal hubs) to allow a quick, convenient and economically justified, from the passenger's perspective, change of the transport mode which would ensure comfort, safety and provide additional services at the same time.

In the context of freight transport multimodality, the Strategy of PKP S.A. indicates the possibility to use well-located properties in order to develop logistics infrastructure facilities, such as logistics parks, handling terminals, warehouses, 
sidings and storage and handling points. The directions defined by the Strategy of PKP S.A. in the area of logistics reflect the assumptions elaborated by PKP S.A. together with the PKP Group companies brought together in the Intermodal Transport Development Plan with a timeframe perspective until 2030. A wide scope of initiatives related to organizing the intermodal logistics chain, financing, investment technology, transport technology, legal solutions as well as innovations, has been adopted as a part of that Plan.

Other significant tasks being a part of the previously described area include coordination of implementation of the European Union legislation within the PKP Group (Directive 2012/34 and the Fourth Railway Package), in particular, interoperability and railway safety. The area also encompasses the participation of the PKP Group in activities related to the investments of Centralny Port Komunikacyjny (CPK) [Solidarity Transport Hub], a High-Speed Rail (HSR) system and the rolling stock development.

A strategic objective is rationalization of the PKP Group management systems through creating a structure that would operate as a holding company, which would serve both implementing business objectives of the railway transport as well as objectives of the national transport policy. Creating a holding structure, in which PKP S.A. would perform the role of a dominant entity will allow an effective implementation of the objectives and tasks of the Strategy of PKP S.A., defined in the preceding areas. It is necessary to implement proper management tools at every level of the process, considering the autonomy of each company in the PKP Group. The role of PKP S.A. as the parent company will be coordination of the Group's activity including but not limited to strategic management, finances, legislation and adjustment to the European Union standards as well as economic cohesion.

The rationalization of the PKP Group management also covers the implementation of projects related to improving the coherence of financial information, including transfer prices, and implementing an IT tool that would improve the Group's reporting processes. PKP S.A. coordinates the project of digitalization of the PKP Group, which will allow an improved use of IT tools within the Group through integrating ICT solutions as well as technology standardization. It is also crucial for the companies to join and use the European Technology Platform on Logistics.

\section{Strategic challenge for rail transport in the area of logistics}

The idea of the Physical Internet (PI) is worth considering to improve the effectiveness and efficiency of transport and logistics processes. The processes of the flow of goods in time and space (transport and logistics), their efficiency and reliability affect the efficiency of business processes and determine the ability to timely and appropriately meet the needs of individual and institutional clients using those services via railway transport.

The Physical Internet is a global system of closely related logistics networks, based on efficiency and reliability. It is based on the use of linked interoperable 
logistics assets which use unified collaboration protocols, intelligent interfaces and a standardized modular transport unit ${ }^{3}$.

Modern transport chains are long and complex, e.g. rail transport chains of the New Silk Road. Some of the fundamental problems that the idea of the Physical Internet can reduce or eliminate include unused space, transport inefficiencies in processes as a result of the lack of integration of systems and the lack of intelligent interfaces (Pękala, 2019).

Figure 1 shows the idea and basic objectives of the Physical Internet.

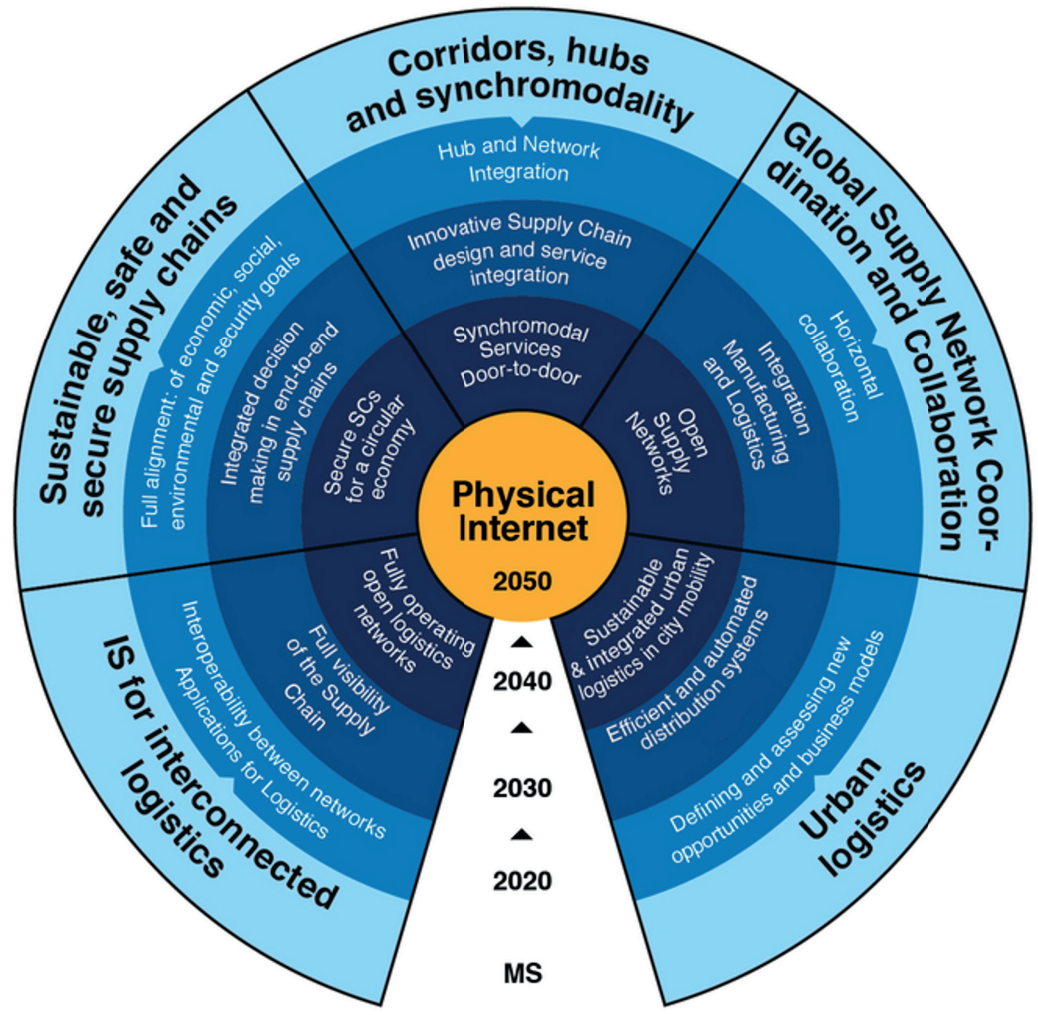

Figure 1. Idea and basic objectives of Physical Internet

Source: (ALICE, 2019)

The basic objectives are:

- more than a twofold increase in the efficiency of logistics (taking into account the benefits of the redirection of the already sent shipments);

- improvement of the reliability of the flow of goods achieved through fast, automated supply chains based on complex information about the difficulties and dangers;

- better use of human resources, hardware and infrastructure;

3 Own elaboration using the definition proposed by B. Montreuil (creator of the concept) (Montreuil et al., 2014). 
- significant reduction of greenhouse gas emission in land transport (PI projects support the EU Horizon 2020 Programme);

- increase in innovative logistics solutions.

"As it appears from research conducted in the U.S., the Physical Internet proposes a system in which the global logistics supply chains are connected by an open intermodal system (road, railway, shipping-barges and ships) that uses standard, modular, reusable containers, identification and coordination of routes in real time by shared logistics centres" (Maxmania, 2012). Producers, shipments senders, transport operators operate independently, using shared logistic networks, which increase the load of vehicles, railcars, boats, and reduce empty mileage of vehicles.

The pillars of the Physical Internet are shown in Figure 2.

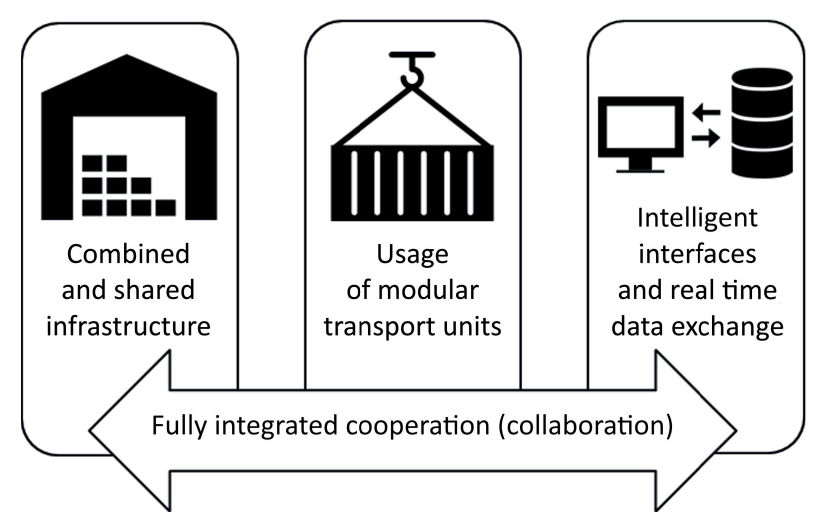

Figure 2. Pillars of Physical Internet

Source: (own elaboration based on: Zdziarska, Hachuła, 2015)

Therefore, the aim of most of the logistics activities in the PKP Group are potential sources of benefits of constructing a global logistics system based on the concept of the Physical Internet:

- a significant increase in the intermodal transport volume obtained by standardization and usage of modular transport units (intermodal is the most prospective segment of rail services);

- generating a huge pool of orders for railway transport as a result of suggesting senders of shipments to plan the decision process via a computer system that takes into account a variety of multimodal options.

For the achievement of these benefits, first and last mile railroad freight terminals, managed within the idea of the Physical Internet, should have adjacent warehouses and a grading plant and increased length of the railway loading track which would enhance capabilities to simultaneously manage and handle the transhipment point of many trucks.

Figure 3 shows a sample layout of a terminal for intermodal rail-road transport. 


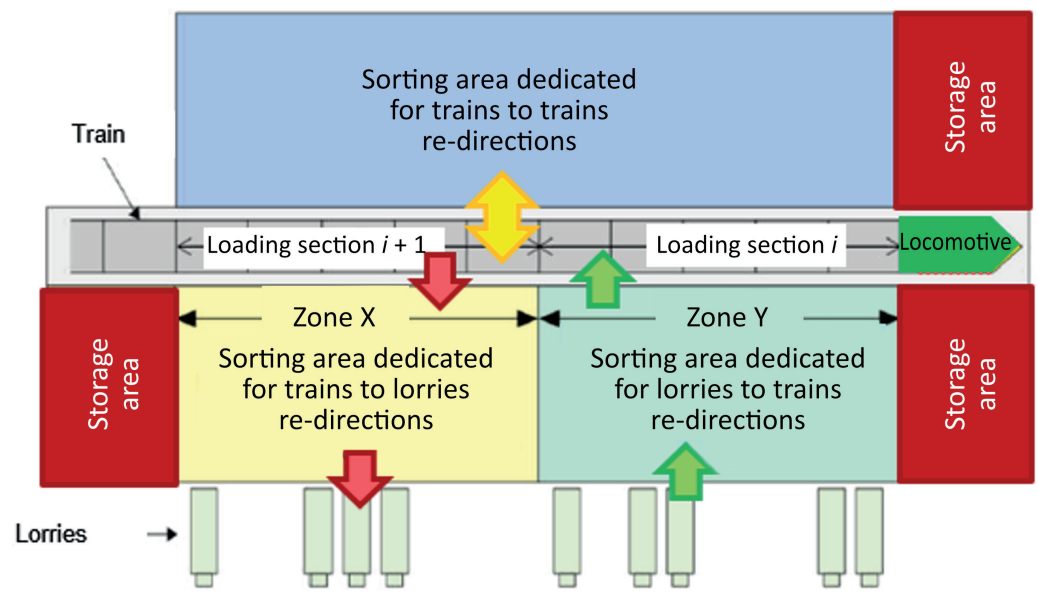

Figure 3. Exemplary layout of a rail-road terminal in the Physical Internet concept Source: (own elaboration based on: Chargui et al., 2018, slide 4)

This idea can be implemented on condition that the clarity of the collaboration rules with various stakeholders is improved in order to acquire goods for common supply chains, integration and implementation of investment processes and business, development of competence and deployment of the latest solutions and techniques to optimize logistics processes, promotion of multi-modal services and organic forms of transport.

\section{Conclusions}

Implementing the Strategy of PKP S.A. will ensure proper preparation of the Polish railway transport for the upcoming challenges. Macroeconomic trends clearly indicate the necessity to develop multimodality of passenger and freight transport. At the same time it is reasonable to take into consideration the fact of continuous globalization and consolidation processes in Europe as well as all over the world, which justifies the need of creating a powerful and integrated railway infrastructure that would operate as a holding company. In terms of cargo logistics, Poland must use the great advantage of its geographical location at the crossing of European corridors: East-West and North-South. When analysing logistics in rail freight transport, the use of the idea of the Physical Internet means introduction of new principles for carriage of cargo, new principles and methods of packing and manipulation of static electricity, the flow of information in standardized protocols in real time and the need to integrate and cooperate links in the entire transport chain. Supporting those main objectives will increase the efficiency of transport and logistics processes and will have a positive effect on the railway transport. Multimodality of passenger transport should be built through railway station investments, which would lead to improved availability and connection of different transport sectors. 


\section{References}

ALICE (Alliance for Logistics Innovation through Collaboration in Europe) (2019). Available from https://www.etp-logistics.eu [Accessed 1 July 2019].

Antonowicz, M. (2018), Presentation at INNOTRANS Fair 2018. Courier RAILWAY, September.

Chargui, T., Bekrar, A., Reghioui, M., Trentesaux, D. (2018), A Mathematical Formulation and Tabu Search Approach for the Road-Rail Assignment, $5^{\text {th }}$ International Physical Internet Conference IPIC, 21 June 2018, Groningen, Netherlands.

Maxmania (2012), Sieć transportu jak internet - megalogistyczny projekt z USA, http:// maxmania.pl/technologie/wystarczy-utworzyc-siec-centrów-logistycznych-które-koordynowałyby-wszelkie-dostepne-usługi-transportowe-w-czasie-rzeczywistym-to-głowny-element-propozycji-grupy-badaczy-z-usa/ [Accessed 1 July 2019].

Montreuil, B., Ballot, E., Meller, R. (2014), Présentation de l'Internet physique, 2e Colloque de l'Ort21 Internet Physique, 27 November 2014, Observatoire Régional des Transports et de la Logistique de Lorraine.

Pękala, M. (2019), The Physical Internet - What Does It Mean?, https://4optima.pl/fizyczny-internet/ [Accessed 11 April 2019].

The Strategy of PKP S.A. (2018), Internal materials of PKP S.A., Warszawa.

Zdziarska, M., Hachuła, P. (2015), Physical Internet-Future Logistics, Conference e-Administration for Business, 14-15 April 2015, Institute of Logistics and Warehousing, Poznań.

\section{Corresponding author}

Mirosław Antonowicz can be contacted at: maaw@kozminski.edu.pl 